\title{
Augmented Reality Mobile Application as Learning Media in Science Subject for the Post Gen Z Generation
}

\author{
Feryanto $^{\text {a }}$ Viola Levi Sunanso ${ }^{\text {a }}$, Michael Vincent ${ }^{a}$, Evan Prasetya ${ }^{a}$, Harco Leslie Hendric Spits \\ Warnars $^{\mathrm{b}^{*}}$, Arief Ramadhan ${ }^{\mathrm{b}}$, Andy Achmad Hendharsetiawan ${ }^{\mathrm{b}}$, Fariza Hanis Abdul Razak ${ }^{\mathrm{c}}$ \\ and Wiranto Herry Utomo ${ }^{d}$
}

Information Systems Department, School of Information Systems, Bina Nusantara University, Jakarta, Indonesia 11480.

${ }^{\mathrm{b}}$ Computer Science Department, BINUS Graduate Program - Doctor of Computer Science, Bina Nusantara University, Jakarta, Indonesia 11480.

${ }^{c}$ Centre for Information Technology Studies, Faculty of Computer and Mathematical Sciences, Universiti Teknologi MARA (UiTM), Shah Alam, Malaysia 40450.

${ }^{\mathrm{d}}$ Department of magister science of information technology, Faculty of Computing, President University, Jawa Barat, Indonesia 17550.

Corresponding author: Harco Leslie Hendric Spits Warnars email: spits.hendric@ binus.ac.id

Article History: Received: 10 November 2020; Revised 12 January 2021 Accepted: 27 January

2021; Published online: 5 April 2021

\begin{abstract}
:
The total population of Indonesia as of September 2020 is based on the official statistical news number 07/01/th. XXIV, 21 January 2021 issued by the Indonesian Statistics Center, totaling 270.20 million people and $10.88 \%$ or 29,397,760 people are the post Gen Z generation born from 2013 onwards with an estimated age up to 7 years of age. The post Gen $\mathrm{Z}$ generation is a generation that is categorized as early childhood. Moreover, learning from an early age is important so that children are familiarized with the knowledge they are most interested in and mastered so that it makes it easier for them to understand it. Especially if the learning material is delivered electronically via a smartphone which is associated with the application of the Augmented Reality (AR) method so that they are more interested in learning and with a different atmosphere in terms of delivering face-to-face subject matter in class which is sometimes boring. In this paper, we design and implement a learning model equipped with AR technology to make it easier for young children to learn subject matter that is important for their future and limited to science subject matter. In this paper, a mobile application with AR technology is proposed where users can learn from the images they capture and gain learning from the perspective of these images. What's more, the application of AR technology is also more practical and reduces the burden of carrying heavy and thick books in studying a subject matter. The model was designed using a use case diagram as a business process design and class diagrams for database design including the user interface as a representation of communication between users and applications.
\end{abstract}

Keywords: Augmented Reality Learning Media, Augmented Reality Mobile Application, Application for students, Information Systems, Application for Early age students.

\section{Introduction}

Education for post Gen $\mathrm{Z}$ generation or recognized as early childhood education or what is known as "Pendidikan Anak Usia Dini (PAUD)" in Indonesian or known as Kindergarten Education or "Taman Kanak-Kanak (TK)" in Indonesian is divided into TK-A and Tk-B where students are 4 to 5 years of age for TK-A and 5 to 6 years for TK-B. This early childhood education is the level of education before entering the 6-year elementary school level which usually starts from the age of 6 to 7 years to start grade 1 of the elementary school (Fajarianto et al., 2018). What is interesting is that early childhood education aims to provide educational stimulation, physical and spiritual growth so that children have the readiness to enter further education, which is organized formally, non-formally, and informally. This regulation on national standards for early childhood education is regulated by Permendikbud article number 137 which is dated 2014 (Hidayat et al., 2020).

In order to prepare great national leaders and prepare human resources who can compete with other nations to become a developed Indonesian state, post Gen $\mathrm{Z}$ generation education must be prepared as early as possible. Moreover, it is equipped with the use of technology as early as possible in learning something so 
that they are familiar with the use of this technology. However, in Indonesia, education for post Gen $\mathrm{Z}$ creation, which amounts to $10.88 \%$ of Indonesia's total population of 270.20 million people, has not been fully carried out by the government and mostly carried out by the private sector, which in this case differs in the way of teaching and delivery (Utami et al., 2021).

In old habits in previous ancient times, such as the 20th century and earlier, using books as a source to study certain materials and information was a habit in the past. Then when the internet appeared, you could access information by making teaching materials and not based on books because nowadays it is increasingly advanced and in technological developments and of course, it is also difficult to find it for reading material. Accessing information is easier and faster because it is assisted by internet speed and also with an affordable smartphone with an easy and affordable internet access speed (Ati et al., 2018).

Based on the problems and issues above in terms of preparing an education that is supported by technology for the post Gen $\mathrm{Z}$ generation or what is known as an early age, we designed a mobile application designed to use this technology to better help users understand learning better. This mobile application was developed as a learning medium that utilizes Augmented Reality (AR) technology so that the teaching and learning process is more interesting because it can display three-dimensional objects that can resemble their original shapes. The learning media in this study are aimed at the post Gen $\mathrm{Z}$ generation or early childhood so they can see, recite, and shape to change the size of objects and be able to play with the objects on display.

Besides, the application of AR in early childhood is still very rare where if using google scholar, a search is carried out in all years which only searches for the words AR and Early childhood in the title of the paper (allintitle: "augmented reality"+"early childhood") then only there were 42 papers with the oldest paper in 2014. Further searches in Indonesian are the words AR and "anak usia dini" in the title of the paper (allintitle: "augmented reality" + "anak usia dini") then obtained 75 papers with the oldest paper in 2010.

\section{Previous Research}

Augmented Reality (AR) was introduced by Louis Rosenberg in 1992 which is a system that applies interactive experiences from real-world environments where objects are in the real world and enhanced by perceptual information generated by computers or systems. AR provides many benefits in the way users access information and this technology can develop rapidly and be used in various areas of life such as marketing, shopping, education, interior, exterior, and others (Costa et al., 2018). The learning method used to support the learning process of teaching activities at this time, especially in science subjects, the introduction of the human digestive organs, still uses books, worksheets, and uses training materials for teaching aids (Khan et al., 2019).

Further research illustrates that the current learning process the teacher writes and explains students then records the material written by the teacher. The teaching aid available is only 1 unit while the number of students in the class is approximately 30 children. Of course, this will create an atmosphere that is less support for students whilst in process learning can be made more rigid result (Lytridis \& Tsinakos, 2018). In addition, using Augmented Reality can change and make the virtual world shown on the screen turn into a real-world and can even try to transform all detected objects into object representations in 3D (Gweon et al., 2018). This is done with the hope that this learning method using AR technology will not be boring and besides that users who are early childhood are interested in exploring deeper into the material being studied, such as recognizing the name of the object displayed and the following information on the object which can be in the form of text, images, videos, and animation. (Maijarern et al., 2018).

Meanwhile, the number of smartphone users is increasing from year to year, where smartphone users consist of children to adults and the number of smartphone users varies according to the needs of users. In its use, based on a study it was found that according to their children they were more interested and happy to use smartphones to play games while according to their parents, their children used smartphones to carry out activities such as playing games, taking photos, listening to songs, and even watching videos. The activities shown from the data provide data where children prioritize playing games as an activity (Markamah et al., 2018).

The results of other studies indicate that several factors determine children's interest in learning with applications. Creating learning applications with interesting and varied games and supported by the provision of learning applications that are more effective and fun for early childhood (Pradibta et al., 2019). 
The development of Augmented Reality is growing and its potential in the future can be seen which will help users to know, obtain, and use information. Application design is designed using Augmented Reality technology as part of a form of review of the learning material being taught. Provide clearer and more detailed information and use games as part of learning (Nurhasanah et al., 2019).

The early origins of Augmented Reality were introduced by Morton Heilig in 1957, where he created Sensorama as an early form of an ongoing form of Augmented Reality called the Virtual Fixture. The development of Augmented Reality is growing and can assist users in knowing, obtaining, and using information, and the design of applications is designed using AR technology as part the learning material being taught (Rahmat et al., 2018).

AR is now widely applied in everyday life, one of which is in the field of education. Currently, AR applications can be integrated to increase the standard of the curriculum used, because the text, images, audio, and video be able to be extended to the student in a real-time environment, so they can learn better (Rohendi \& Wihardi, 2020). Notebooks and other teaching aids can be marked that, if scanned with an AR device, will be able to produce additional information to students which are displayed in multimedia form (Syahidi et al., 2019). In other research. With AR, students will be able to view computer-generated simulations of important history, parts, and organs of the human body, spatial shapes, or geometry in greater depth. At the higher education level, many applications can be used, for example, the Studiestube's Construct3D. Construct3D helps students learn about concepts rather than mechanical engineering, mathematics, and geometry. This is a very good process where students can learn to use technology (Syawaludin et al., 2019).

The following are some studies that apply AR technology to create applications that can be used by early childhood and several studies on the application of AR have been applied to early childhood were surveyed based on research papers between 2009 and 2018 as many as 24 papers which show possibility research in AR for early childhood (Tang et al., 2019). Furthermore, based on the results of the paper collection, it was found that research on the application of AR in early childhood has increased slowly in the last ten years, and most of its applications are in the field of early literacy, which is a marker-based AR model, and mostly implemented in mobile applications (Masmuzidin \& Aziz, 2018). Based on the virtualization scenario in AR which is integrated into early childhood education, there are several similarities in characteristics including in terms of situational learning theory, and terms of virtual learning scenarios with the AR approach (Kuang \& Bai, 2019). To create and design AR applications used by early childhood, it is necessary to pay attention to 7 things, namely emphasizing AR elements for early childhood education purposes, ensuring AR elements encourage early childhood learning interest, connecting what is seen on the screen with the surrounding environment, stimulating interaction social between early childhood, easy to use by early childhood, providing guidance not only to early childhood but also adults and always following the latest developments (Oranç \& Küntay, 2019).

There is some implementation where using AR flash card which combines with a mobile application where the AR flash card was scan. Firstly, a mobile application equipped with AR called "Tilsimli arifler" was developed by researchers in Greece to help young children learn letters as early characters to be recognized by early childhood using the unity and Vuforia SDK tools. In addition, the image processing algorithm is used to recognize the character letters that are taken using the camera and searched in the local database which stores all introduced letters (Ablyaev et al., 2019). Moreover, a survey was conducted of 98 early childhood and 4 teaching teachers in Macau, China where the survey assessed the application of learning letters for early childhood using AR flash cards where the AR flash cards can be scanned using a mobile phone to display their features in 3D. The survey results show that the use of AR flash cards further increases the interest and interest of early childhood in learning subject matter (R. W. Chen \& Chan, 2019).

Some paper discusses the implementation of AR for English learning for early childhood. For example, there is another study using a mobile application that also uses AR cards to teach simple words of English to early childhood in Wuhan, China. The mobile application will scan the AR card and the mobile 
application will display a scene and a 3D word model along with the pronunciation of the English words (Y. Chen et al., 2017). Learning how to read English words or learn English vocabulary for early childhood was developed by applying AR to a mobile application in Hong Kong, China, where its use is under the supervision of their parents. The prototype was developed with the unity game engine including implementation Kudan AR plugin, where the camera will detect objects around it and learn each object marked, if it is there, the pronunciation will be displayed in English, and if not then it will be saved automatically by the admin and will be done the labeling process of these images for future identification (Lee et al., 2017). Moreover, a survey was conducted by researchers in Spain, where a comparison was made of the early childhood group which was divided into 50 and 52 early childhood to pay attention to the success of the application of AR for learning English for early childhood. The results showed the use of AR in learning English subject matter increased early childhood interest and relationships in learning (Redondo et al., 2020).

Furthermore, the implementation of AR to study the forms of objects which are living things is also developed and is limited to the introduction of animal types. A study using a mobile application equipped with AR to identify animals for early childhood by applying the six-step Multimedia Development Life Cycle (MDLC) methodology where animal image data is collected and labeled and a display is made that early childhood can trace. to get to know the animals (Dewana et al., 2020). Furthermore, another study provides an introduction to animals in 3D for early childhood in writing, sound, images, video, and animation applied to Unity 3D and the Vuforia SDK, which in its application uses a fast corner detection algorithm for precision shooting with the camera (Nainggolan et al., 2018).

\section{Proposed Model}

The application that is built is designed to be used so that users can use the application to take a picture of the surrounding environment and perform a scan so that the name and description of the product appear. The main part of the menu or homepage has developed and completed subjects for users who in this case are early childhood. In lessons that require practice, the application will provide a lab function to practice from the user's smartphone and this application also features sharing features with fellow friends. Furthermore, the proposed system modeling will be displayed using Unified Modeling Languages (UML) where use case diagrams are used to describe the processes that occur in the proposed application, then apply class diagrams to model database model table relationships and do not miss including a user interface (UI) which used as a screen model design which is a communication between the user and the application used.



Figure 1. Use case diagram of the proposed model 
The Use Case Diagram as seen in Figure 1 shows the steps of the proposed model which is equipped with AR technology in the proposed Cellular Application and there are 6 steps of the use case as shown in Figure 1, starting from opening the application on the main menu display which can be seen in Figure 2a. In Figure 2a's User Interface (UI), users can choose between login and signup where new users must choose signup where the UI will be displayed in Figure $2 \mathrm{~b}$ where they must enter data such as name, email, password, gender, date of birth and a telephone number that can be contacted. As for registered users, they can enter the system by selecting login in Figure $2 b$ and the UI will change as shown in Figure $2 c$ where registered users have to enter their registered email and password and the system will check the database if they enter the valid email and password.

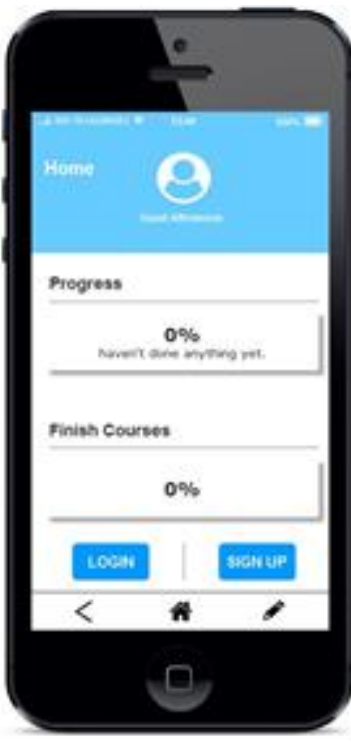

(a)

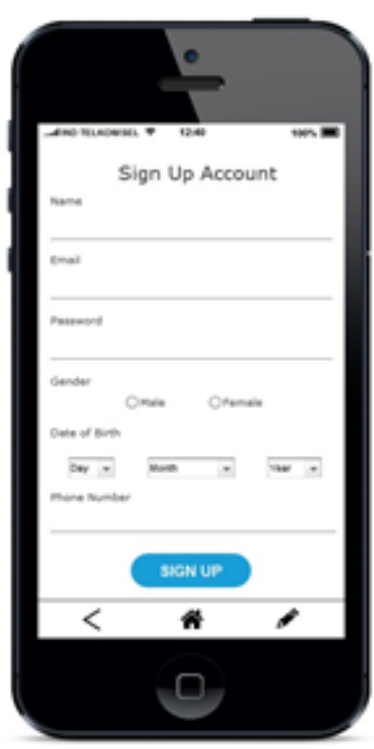

(b)

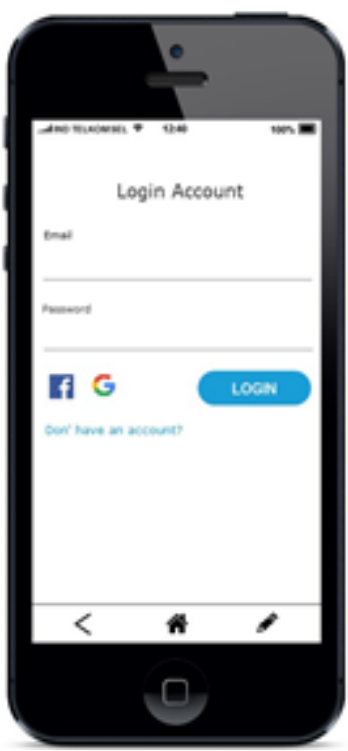

(c)

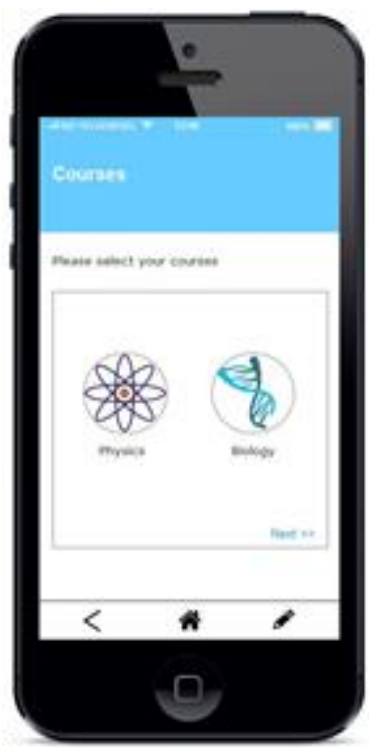

(d)

Figure 2. (a) User Interface of The Main Menu, (b) User Interface of Registration Account, (c) User Interface of Login Account, (d) User Interface of Select Courses

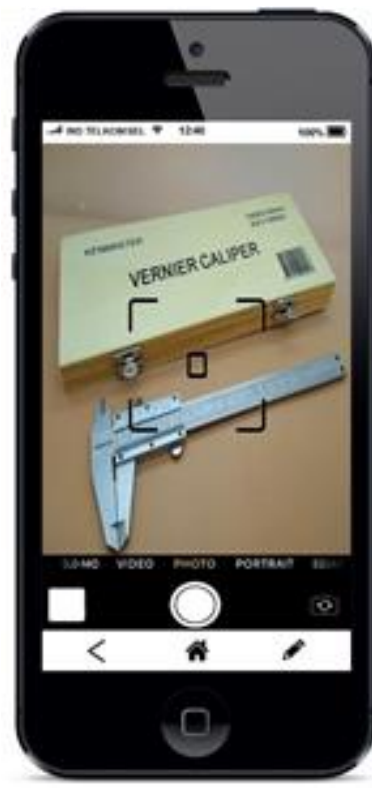

(a)

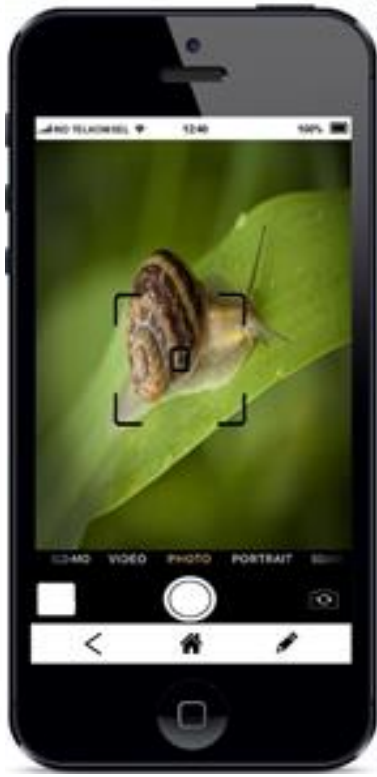

(b)

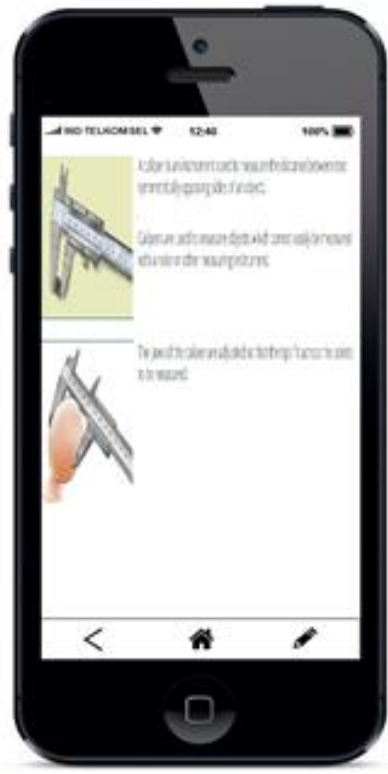

(c)

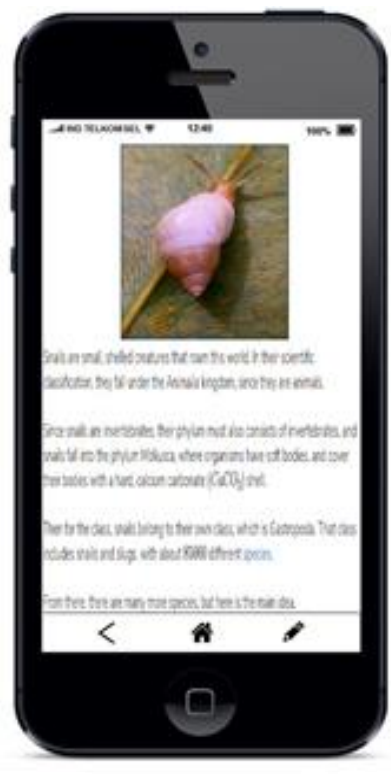

(d)

Figure 3. (a) User Interface do a Scanner the Image on Physics, (b) User Interface do a Scanner the Image on Biology, (c) User Interface Information of Physics, (d) User Interface Information of Biology 
If the user has a valid email and password, early childhood users can choose what subjects to study and in this case, are limited to terms of physics and biology as shown in Figure 2d. After that, the user will be asked to use a smartphone camera to take pictures around him as seen in Figures $3 \mathrm{a}$ and $3 \mathrm{~b}$, where Figure $3 a$ is an example for physics subjects while Figure $3 b$ is an example for biology subjects. Every image taken by the cellphone camera will be saved and searched for in the database store and if the scanned image matches the image stored in the database, the UI display will change to look like figures $3 \mathrm{c}$ and $3 \mathrm{~d}$, where figure $3 \mathrm{c}$ is for the scanned results on the UI figure $3 \mathrm{a}$ while the figure $3 \mathrm{~d}$ for the scan results in the UI figure $3 \mathrm{~b}$. However, if the scanned image is searched for in the database store and does not match, the image will be saved in the database as a new entity and the admin will then do the labeling process manually. For currently, the information is only limited to text and image only where in the future we are interested as well to include with any information such as video and animation.

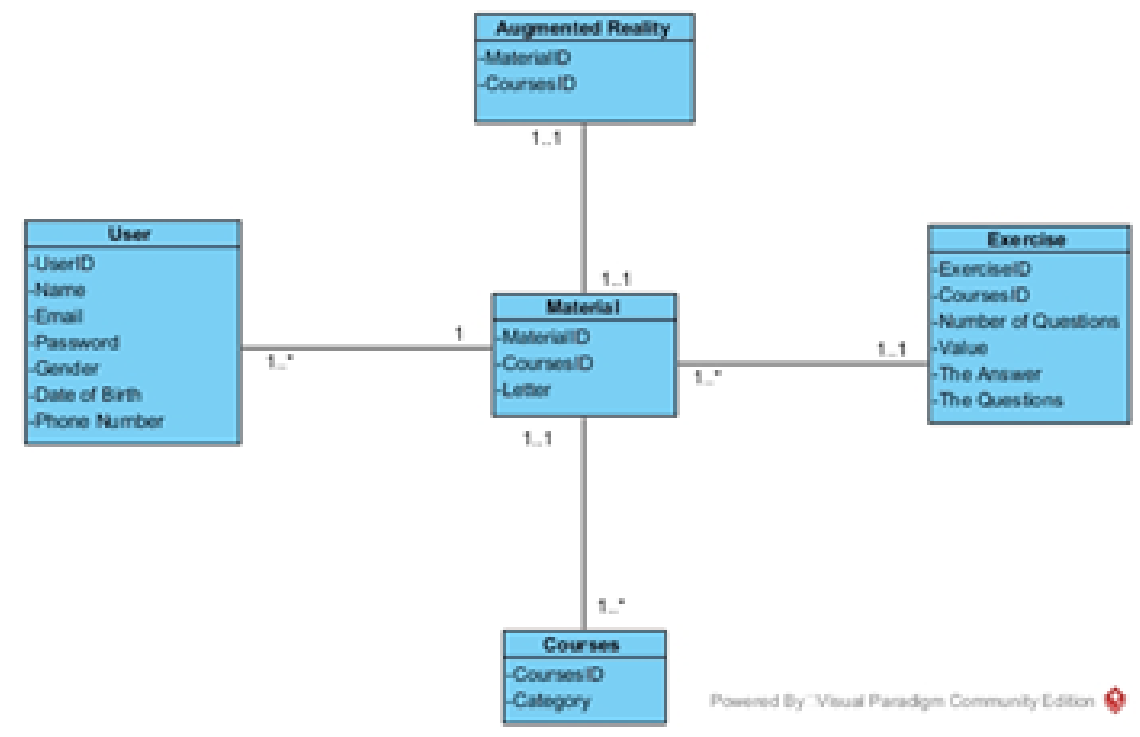

Figure 4. Class diagram of the proposed model

Whereas Figure 4 is a class diagram showing the entity class diagram which aims to show the class relations, each of which is represented as a table in the database. In the database design model, as shown in Figure 4, there are 5 classes or 5 tables, namely Users, Materials, Exercises, Courses, and Augmented Reality. The following is a detailed description of each class or table:

\section{Table User}

In the user table, there are various types of attributes, there are UserID, Name, Email, Password, Gender, Date of Birth, and Phone Number. This attribute is so that the system knows about user information that uses Mobile Application Augmented Reality. And then in multiplicity from user to material 1 (One), while material to user 1..* (One to Many), because one user has a lot of material while many materials only have one user.

\section{Table Material}

In the material table, there are several types of attributes, namely Material, Program ID, and also the content of the material that will be carried out by the user and so that users also see it in more detail to see this material. And then in table multiplicity material to exercises $1 . .1$ (One to One) while exercises to material $1 . . *$ (One to Many), because one material has many exercises while many exercises have only one material.

\section{Table Courses}

In the course section, users can also see how the course and categories are. And then in the multiplicity from courses to material, namely $1 . .1$ (One to One), while from material to courses it is 1 ...* (One to Many) because one course has a lot of material while many materials have only one course.

\section{Table Exercise}

The next table is table Exercises. In the table, exercises are content attributes such as Course IDs, Number of Questions, Value, The Answers, and The questions. The relationship of multiplicity in the 
table exercises to the material is $1 . .^{*}$ (One to Many), while the material for the exercises is $1 . .1$ (One to One). We will explain that the exercises have a lot of material while many materials only have one exercise.

5. Table Augmented Reality

And the last is the Augmented Reality table itself. And the last one is the Augmented Reality table itself. In the following table, the attributes are materialID and coursesID, the multiplicity relation is from the augmented reality table to the material 1..1 (One to One), while from the material to the augmented reality $1 . .1$ (One to One) also.

\section{Conclusion}

With this conclusion that Augmented Reality technology has a positive and negative impact as well. Because at an early age, all of them are already using and relying on technology, especially those that are so advanced, developing, and rapid. At least make this application or make it so that among the present times become more interested in learning to use AR. If in the past in searching for information must use book media, now it can easily do learning by using internet media especially already equipped with Augmented Reality technology.

The number of smartphone users continues to grow from time to time. Therefore learning applications are very helpful for everyone in learning. With a combination of Augmented Reality technology, users can take pictures around it and find out an explanation of the images they take interested in learning to use AR, and in the future, we returned to other courses.

\section{Acknowledgments}

This work is supported by the Research and Technology Transfer Office, Bina Nusantara University as a part of Bina Nusantara University's International Research Grant contract number: No.017/VR.RTT/III/2021 contract date: 22 March 2021.

\section{References}

[1]. Ablyaev, M., Abliakimova, A., \& Seidametova, Z. (2019). Design of Mobile Augmented Reality System for Early Literacy. ICTERI, 274-285.

[2]. Ati, M., Kabir, K., Abdullahi, H., \& Ahmed, M. (2018). Augmented reality enhanced computer aided learning for young children. 2018 IEEE Symposium on Computer Applications \& Industrial Electronics (ISCAIE), 129-133.

[3]. Chen, R. W., \& Chan, K. K. (2019). Using augmented reality flashcards to learn vocabulary in early childhood education. Journal of Educational Computing Research, 57(7), 1812-1831.

[4]. Chen, Y., Zhou, D., Wang, Y., \& Yu, J. (2017). Application of augmented reality for early childhood English teaching. 2017 International Symposium on Educational Technology (ISET), 111-115.

[5]. Costa, M. C., Patrício, J. M., Carrança, J. A., \& Farropo, B. (2018). Augmented reality technologies to promote STEM learning. 2018 13th Iberian Conference on Information Systems and Technologies (CISTI), 1-4.

[6]. Dewana, R., Komansilan, T., Togas, P., \& Liando, O. E. S. (2020). Development Multimedia Learning of Introduction of Animals using Augmented Reality Technology for Early Childhood Education Programs.

[7]. Fajarianto, O., Setiawan, M. I., Mursidi, A., Sundiman, D., \& Sari, D. A. P. (2018). The Development of learning materials for introduction of animals in early childhood using augmented reality. International Conference on Knowledge Management in Organizations, 722-727.

[8]. Gweon, G., Kim, B., Kim, J., Lee, K. J., Rhim, J., \& Choi, J. (2018). MABLE: Mediating Young Children's Smart Media Usage with Augmented Reality. Proceedings of the 2018 CHI Conference on Human Factors in Computing Systems, 1-9.

[9]. Hidayat, W. N., Damayanti, H., Pratiwi, L. S., Sutikno, T. A., \& Patmanthara, S. (2020). Fun Learning with Flashcard using Augmented Reality for Learning Daily Prayers of Kindergarten Students. 2020 3rd International Conference on Computer and Informatics Engineering (IC2IE), 349-354.

[10]. Khan, T., Johnston, K., \& Ophoff, J. (2019). The impact of an augmented reality application on learning motivation of students. Advances in Human-Computer Interaction, 2019.

[11]. Kuang, Y., \& Bai, X. (2019). The feasibility study of augmented reality technology in early childhood education. 2019 14th International Conference on Computer Science \& Education (ICCSE), 172-175.

[12]. Lee, L.-K., Chau, C.-H., Chau, C.-H., \& Ng, C.-T. (2017). Using augmented reality to teach kindergarten students English vocabulary. 2017 International Symposium on Educational Technology 
(ISET), 53-57.

[13]. Lytridis, C., \& Tsinakos, A. (2018). Evaluation of the ARTutor augmented reality educational platform in tertiary education. Smart Learning Environments, 5(1), 1-15.

[14]. Maijarern, T., Chaiwut, N., \& Nobnop, R. (2018). Augmented reality for science instructional media in primary school. 2018 International Conference on Digital Arts, Media, and Technology (ICDAMT), 198-201.

[15]. Markamah, N., Subiyanto, S., \& Murnomo, A. (2018). The Effectiveness of Augmented Reality App to Improve Students Achievement in Learning Introduction to Animals. Journal of Education and Learning (EduLearn), 12(4), 651-657.

[16]. Masmuzidin, M. Z., \& Aziz, N. A. A. (2018). The current trends of augmented reality in early childhood education. The International Journal of Multimedia \& Its Applications (IJMA), 10(6), 47.

[17]. Nainggolan, E. R., Asymar, H. H., Nalendra, A. R. A., Sulaeman, F., \& Radiyah, U. (2018). The implementation of augmented reality as learning media in introducing animals for early childhood education. 2018 6th International Conference on Cyber and IT Service Management (CITSM), 1-6.

[18]. Nurhasanah, Z., Widodo, A., \& Riandi, R. (2019). Augmented reality to facilitate students' biology mastering concepts and digital literacy. JPBI (Jurnal Pendidikan Biologi Indonesia), 5(3), 481-488.

[19]. Oranç, C., \& Küntay, A. C. (2019). Learning from the real and the virtual worlds: Educational use of augmented reality in early childhood. International Journal of Child-Computer Interaction, 21, 104111.

[20]. Pradibta, H., Nurhasan, U., Pramesti, T. D., \& Suryadi, S. B. (2019). "Hijaiyah" interactive learning for pre-school students. Journal of Physics: Conference Series, 1402(6), 66050.

[21]. Rahmat, R. F., Akbar, F., Syahputra, M. F., Budiman, M. A., \& Hizriadi, A. (2018). An interactive augmented reality implementation of hijaiyah alphabet for children education. Journal of Physics: Conference Series, 978(1), 12102.

[22]. Redondo, B., Cózar-Gutiérrez, R., González-Calero, J. A., \& Ruiz, R. S. (2020). Integration of augmented reality in the teaching of English as a foreign language in early childhood education. Early Childhood Education Journal, 48(2), 147-155.

[23]. Rohendi, D., \& Wihardi, Y. (2020). Learning Three-Dimensional Shapes in Geometry Using MobileBased Augmented Reality. International Journal of Interactive Mobile Technologies, 14(9).

[24]. Syahidi, A. A., Tolle, H., Supianto, A. A., \& Arai, K. (2019). AR-Child: Analysis, Evaluation, and Effect of Using Augmented Reality as a Learning Media for Preschool Children. 2019 5th International Conference on Computing Engineering and Design (ICCED), 1-6.

[25]. Syawaludin, A., Gunarhadi, G., \& Rintayati, P. (2019). Enhancing elementary school students' abstract reasoning in science learning through augmented reality-based interactive multimedia. Jurnal Pendidikan IPA Indonesia, 8(2), 288-297.

[26]. Tang, T. Y., Xu, J., \& Winoto, P. (2019). An augmented reality-based word-learning mobile application for children with autism to support learning anywhere and anytime: object recognition based on deep learning. International Conference on Human-Computer Interaction, 182-192.

[27]. Utami, F., Andika, W. D., \& Sumarni, S. (2021). Introduction to Sea Animals With Augmented Reality Based Flashcard for Early Childhood. 4th Sriwijaya University Learning and Education International Conference (SULE-IC 2020), 215-220. 